\title{
Carboplatin Plus Nab-paclitaxel in Performance Status 2 Patients With Advanced Non-small-cell Lung Cancer
}

\author{
KAZUHISA NAKASHIMA ${ }^{1}$, HIROAKI AKAMATSU ${ }^{2}$, HARUYASU MURAKAMI ${ }^{1}$, \\ TAKASHI NIWA ${ }^{3}$, YASUO IWAMOTO ${ }^{4}$, YUICHI OZAWA ${ }^{2}$, TOSHIHIDE YOKOYAMA ${ }^{3}$, \\ HIROYASU SHODA ${ }^{5}$, NOBUYUKI YAMAMOTO ${ }^{2}$, HIROSHIGE YOSHIOKA ${ }^{3}$, \\ KEN MASUDA $^{5}$, TATEAKI NAITO $^{1}$, KEITA MORI $^{6}$ and TOSHIAKI TAKAHASHI ${ }^{1}$ \\ ${ }^{1}$ Division of Thoracic Oncology, Shizuoka Cancer Center, Shizuoka, Japan; \\ ${ }^{2}$ Internal Medicine III, Wakayama Medical University, Wakayama, Japan; \\ ${ }^{3}$ Department of Respiratory Medicine, Kurashiki Central Hospital, Kurashiki, Japan; \\ ${ }^{4}$ Department of Medical Oncology, Hiroshima City Hospital, Hiroshima, Japan; \\ ${ }^{5}$ Department of Respiratory Medicine, Hiroshima City Hospital, Hiroshima, Japan; \\ ${ }^{6}$ Clinical Research Center, Shizuoka Cancer Center, Shizuoka, Japan
}

\begin{abstract}
Background/Aim: This phase I/II study aimed at assessing the efficacy of combination therapy with carboplatin (CBDCA) on day 1 and nab-paclitaxel (Nab$P T X)$ on days 1 and 8 of a 21-day cycle in performance status (PS) 2 patients with non-small-cell lung cancer (NSCLC). Patients and Methods: PS 2 patients with NSCLC were enrolled into a phase I study using a $3+3$ design. Once the recommended phase II dose (RP2D) was established, the patients were enrolled into phase II. Results: Based on the phase I findings, the RP2D was determined as $C B D C A$ area under the curve $6 \mathrm{mg} / \mathrm{ml} / \mathrm{min}$ and Nab-PTX $100 \mathrm{mg} / \mathrm{m}^{2}$. In the phase II part, 27 patients were evaluable. The overall response rate was 44\%. The median progressionfree survival and overall survival were 5.2 months and 14.0 months, respectively. There was no treatment-related death. Conclusion: CBDCA plus Nab-PTX therapy is a promising treatment strategy for PS 2 patients with NSCLC.
\end{abstract}

Platinum combination chemotherapy is a standard treatment for patients with advanced non-small-cell lung cancer (NSCLC) and a good performance status (PS) (1). The recent development of less-toxic platinum combinations has broadened the indication to patients with a poor PS, such as an Eastern Cooperative Oncology Group (ECOG) PS of 2. For

Correspondence to: Kazuhisa Nakashima, MD, Division of Thoracic Oncology, Shizuoka Cancer Center, 1007, Shimonagakubo, Nagaizumi-cho, Sunto-gun, Shizuoka, Japan. Tel: +81 559895222, Fax: +81 559895783, e-mail: ka.nakashima@scchr.jp

Key Words: Non-small-cell lung cancer, performance status, carboplatin, nab-paclitaxel. example, one study reported that the combination of carboplatin (CBDCA) plus pemetrexed therapy is more effective than pemetrexed alone among patients with advanced NSCLC and a PS of 2 (2). However, 4\% treatment-related deaths in the CBDCA and pemetrexed therapy arm occurred in that study. Patients with a PS of 2 have increased risks of adverse events (3). Moreover, patients with NSCLC are often ineligible for pemetrexed because of having squamous cell carcinoma $(\mathrm{Sq})$, interstitial pneumonia, or impaired renal function (4-6), and thus the standard treatment modality for NSCLC patients with PS 2 is yet to be established.

For patients with advanced NSCLC and PS 0 or 1 , CBDCA plus nab-paclitaxel (Nab-PTX) yielded significantly higher overall response rates (ORR) and a non-significant 1-month improvement in median overall survival (OS) than CBDCA plus paclitaxel in a phase III study (CA031 study) (7). The subset analysis also demonstrated the safety and efficacy of CBDCA plus Nab-PTX in an elderly subgroup (8). CBDCA plus Nab-PTX treatment may be effective and tolerable for NSCLC patients with PS 2. However, the treatment schedule needed to be modified in most patients who received CBDCA area under the curve (AUC) 6 on day 1 plus Nab-PTX $100 \mathrm{mg} / \mathrm{m}^{2}$ on days 1,8 , and 15 of a 21 day cycle in a phase III study (7).

Therefore, this phase I/II study aimed to assess the safety and efficacy of combination therapy with CBDCA on day 1 and Nab-PTX on days 1 and 8 of a 21-day cycle for advanced NSCLC patients with PS 2.

\section{Patients and Methods}

Patient selection. The eligibility criteria were 1) age 20 years or older; 2) histologically- or cytologically-confirmed cytotoxic 
chemotherapy-naive advanced (Stage IIIB, IV, postoperative recurrence, or recurrence after radiotherapy) NSCLC; 3) ECOG PS 2 (PS was assessed by more than 2 doctors); 4) evaluable lesions and adequate organ function; and 5) life expectancy of more than 12 weeks. All patients provided written informed consent.

Patients were excluded if they had 1) symptomatic brain metastasis; 2) interstitial pneumonia with usual interstitial pneumonia pattern on chest computed tomography; 3) uncontrolled pleural effusion, ascites or pericardial effusion; 4) received palliative radiotherapy within the past two weeks; 5) active concomitant malignancy; 6) severe complication; 7) positivity for hepatitis B surface antigen; 8) a history of previous severe drug allergy; 9) receiving continuous systemic administration of steroid; and 10) were pregnant or breastfeeding.

Study treatment. Patients received CBDCA on day 1 and Nab-PTX on days 1 and 8 every 21 days for $4-6$ cycles. In the phase I trial, patients were enrolled in the dose escalation cohorts using a $3+3$ design with a starting dose of CBDCA AUC 5 plus Nab-PTX $100 \mathrm{mg} / \mathrm{m}^{2}$ (level 0 cohort). Dose-limiting toxicity (DLT) was assessed during cycle 1. DLT was considered to be any of the following adverse events: grade 4 (Common Terminology Criteria for Adverse Events ver. 4.0) neutropenia for $\geq 5$ days, grade 3 or 4 febrile neutropenia, grade 4 thrombocytopenia, and grade 3 nonhematological toxicity for $\geq 5$ days Patients who did not receive Nab-PTX on day 8 for reasons other than DLT were excluded from the evaluation of DLT.

If more than $33 \%$ of patients receiving level 0 chemotherapy developed DLT, the dose was deescalated to CBDCA AUC 5 plus Nab-PTX $75 \mathrm{mg} / \mathrm{m}^{2}$ (level -1 cohort). If less than $33 \%$ of patients receiving level 0 chemotherapy developed DLT, the dose was escalated to CBDCA AUC 6 plus Nab-PTX $100 \mathrm{mg} / \mathrm{m}^{2}$ (level +1 cohort).

If more than $33 \%$ of patients receiving level -1 chemotherapy developed DLT, the RD could not be defined, and no phase II trial would be conducted. If less than $33 \%$ of patients receiving level -1 chemotherapy developed DLT, level -1 was considered to be the RD.

If more than $33 \%$ of patients receiving level +1 chemotherapy developed DLT, level 0 was considered to be the RD. If less than $33 \%$ of patients receiving level +1 chemotherapy developed DLT, level +1 was considered to be the RD

In the phase II trial, patients received CBDCA plus nab-PTX treatment with the RD.

Ethics. This study complied with all the principles in the Declaration of Helsinki and has been approved by the institutional review board. All enrolled patients provided written informed consent. This trial was registered with the University Hospital Medical Information Network (UMIN) clinical trial registry (no. UMIN000014544).

Statistical analysis (Phase II). The primary endpoint of the phase II trial was progression-free survival (PFS). In a previous study, the median PFS was 2.9 months for the CBDCA plus PTX therapy for Japanese patients with NSCLC and PS 2 (9). Therefore, the PFS threshold of 3.0 months and an expected PFS of 6 months was set for the present study. To reach $10 \%$ (one-sided) significance and $80 \%$ statistical power, a minimum sample size of 24 patients was calculated to be required (10). Assuming a $10 \%$ exclusion rate, the planned sample size was 27 patients. Patients who were treated with $\mathrm{RD}$ in the phase I trial were included in the analysis of the phase II
Table I. Patient characteristics.

\begin{tabular}{|c|c|c|}
\hline & $\begin{array}{c}\text { Phase I trial } \\
\quad \mathrm{N}=10\end{array}$ & $\begin{array}{c}\text { Phase II trial } \\
\mathrm{N}=27\end{array}$ \\
\hline \multicolumn{3}{|l|}{ Age, years } \\
\hline Median (range) & $70(55-79)$ & $69(48-78)$ \\
\hline \multicolumn{3}{|l|}{ Gender } \\
\hline Male & 5 & 17 \\
\hline Female & 5 & 10 \\
\hline \multicolumn{3}{|l|}{ Stage } \\
\hline IIIB & 0 & 2 \\
\hline IV & 8 & 21 \\
\hline Postoperative recurrence & 2 & 3 \\
\hline Recurrence after radiotherapy & 0 & 1 \\
\hline \multicolumn{3}{|l|}{ Histology } \\
\hline Squamous cell carcinoma & 2 & 5 \\
\hline Adenocarcinoma & 8 & 20 \\
\hline Others & 0 & 2 \\
\hline \multicolumn{3}{|l|}{ Mutation } \\
\hline EGFR Exon20 insertion & 2 & 3 \\
\hline EGFR Exon 18 G719X & 0 & 1 \\
\hline Negative & 8 & 23 \\
\hline \multicolumn{3}{|l|}{ Previous therapy } \\
\hline Immune check point inhibitor & 0 & 1 \\
\hline None & 10 & 26 \\
\hline \multicolumn{3}{|l|}{ Comorbidity or previous illness } \\
\hline Hypertension & 2 & 5 \\
\hline Diabetes mellitus & 3 & 7 \\
\hline Heart disease & 2 & 5 \\
\hline Lung disease & 3 & 4 \\
\hline Other cancer & 2 & 4 \\
\hline
\end{tabular}

Table II. Treatment response in the phase II trial.

\begin{tabular}{lc}
\hline & $\mathrm{N}=27$ \\
\hline Complete response & 0 \\
Partial response & 12 \\
Stable disease & 11 \\
Progressive disease & 4 \\
Overall response rate $(95 \% \mathrm{CI})$ & $44 \%(28 \%-63 \%)$ \\
Disease control rate $(95 \% \mathrm{CI})$ & $85 \%(68 \%-94 \%)$ \\
\hline
\end{tabular}

trial. All analyses were performed using JMP software (version 10.0; SAS Institute Inc., Cary, NC, USA).

\section{Results}

Patient characteristics. In total, 31 patients were enrolled from July 2014 through February 2018 in this study. The patient characteristics are listed in Table I. Ten patients were enrolled in the phase I trial. Twenty-seven patients, which included 6 patients from the phase I trial who were treated with the RD level, were enrolled in the phase II trial. 


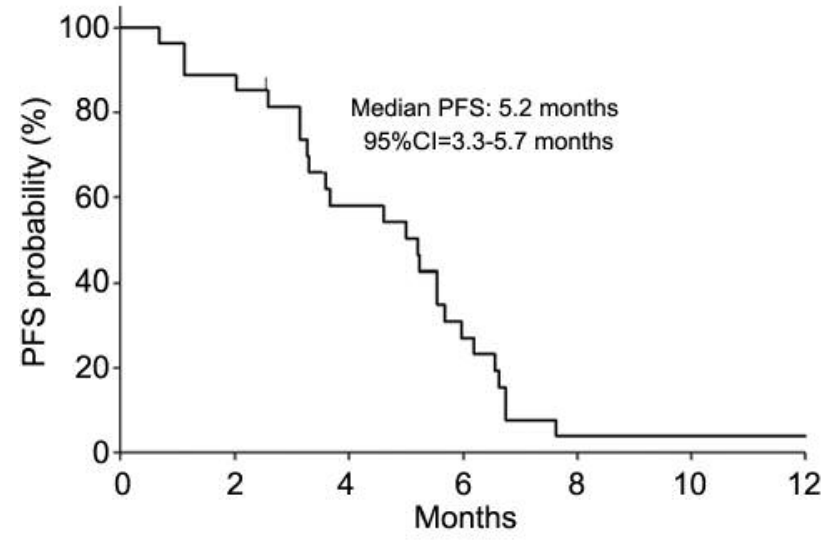

Figure 1. Kaplan-Meier curve of progression-free survival (PFS).

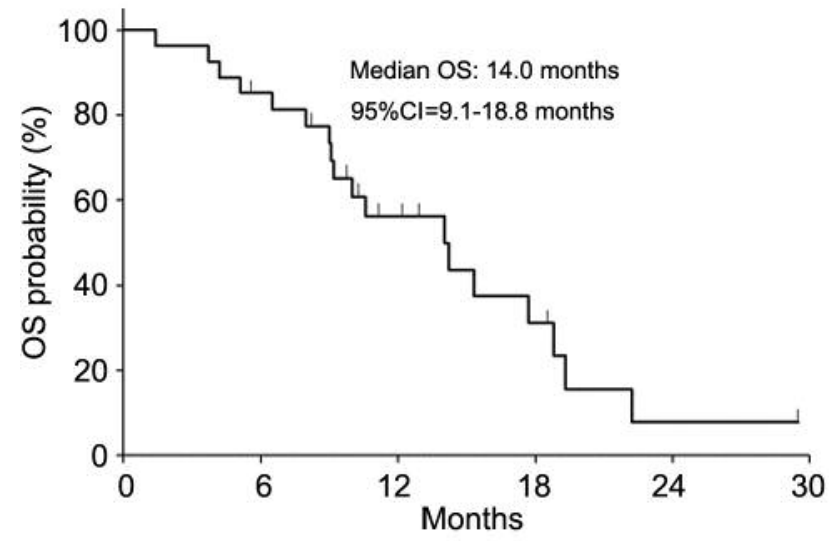

Figure 2. Kaplan-Meier curve of overall survival (OS).

Efficacy. The objective tumor responses are summarized in Table II. The ORR was $44 \%$ (95\% confidence interval $(\mathrm{CI})=28 \%-63 \%$, while the disease control rate was $85 \%$. The ORRs in patients with Sq and non-Sq were $40 \%$ and $45 \%$, respectively. The median PFS for all patients was 5.2 months (95\% CI=3.3-5.7 months) (Figure 1). The median PFS in patients with $\mathrm{Sq}$ and non-Sq were 3.7 months and 5.2 months, respectively $(p=0.78)$.

In the phase II trial, 17 patients (63\%) received post-study treatment chemotherapy. Nine patients $(33 \%)$ were treated with immune checkpoint inhibitor.

The median OS for all patients was 14.0 months (95\% CI=9.1-18.8 months) (Figure 2). The median OS in patients with $\mathrm{Sq}$ and non-Sq were 9.0 months and 14.2 months, respectively ( $p=0.087)$.

The PS of 13 patients (48\%) improved from 2 to a score of 1 .

Adverse events. The adverse events experienced by patients during the treatment are shown in Table III. The incidence of grade 3 or 4 hematological adverse events was $73 \%$. The incidence of grade 3 non-hematological adverse events was $37 \%$, while none of the patients experienced grade 4 nonhematological adverse events. The most common grade 3 or 4 adverse events were neutropenia (60\%), leukopenia (45\%), anemia $(30 \%)$, thrombocytopenia $(22 \%)$, anorexia $(15 \%)$, and fatigue $(15 \%)$. Two patients experienced grade 3 febrile neutropenia. None of the patients experienced grade 5 adverse events.

\section{Discussion}

In the phase I trial, the RD for the phase II trial of CBDCA and Nab-PTX was determined to be CBDCA AUC 6 and 
Table III. Adverse events in the phase II trial.

\begin{tabular}{|c|c|c|c|c|c|}
\hline & All & Grade 1 & Grade 2 & Grade 3 & Grade 4 \\
\hline \multicolumn{6}{|c|}{ Hematologic adverse events } \\
\hline Anemia & $26(96 \%)$ & $5(19 \%)$ & $13(48 \%)$ & $8(30 \%)$ & $0(0 \%)$ \\
\hline Leucopenia & $24(89 \%)$ & $5(19 \%)$ & $7(26 \%)$ & $8(30 \%)$ & $4(15 \%)$ \\
\hline Neutropenia & $23(85 \%)$ & $3(11 \%)$ & $4(15 \%)$ & $8(30 \%)$ & $8(30 \%)$ \\
\hline Thrombocytopenia & $17(63 \%)$ & $5(19 \%)$ & $6(22 \%)$ & $6(22 \%)$ & $0(0 \%)$ \\
\hline Febrile neutropenia & $2(7 \%)$ & - & - & $2(7 \%)$ & $0(0 \%)$ \\
\hline \multicolumn{6}{|c|}{ Nonhematologic adverse events } \\
\hline Anorexia & $19(70 \%)$ & $6(22 \%)$ & $9(33 \%)$ & $4(15 \%)$ & $0(0 \%)$ \\
\hline Fatigue & $16(59 \%)$ & $6(22 \%)$ & $6(22 \%)$ & $4(15 \%)$ & $0(0 \%)$ \\
\hline Nausea & $14(52 \%)$ & $7(26 \%)$ & $5(19 \%)$ & $2(7 \%)$ & $0(0 \%)$ \\
\hline Alopecia & $14(52 \%)$ & $6(22 \%)$ & $8(30 \%)$ & - & - \\
\hline Diarrhea & $8(30 \%)$ & $7(26 \%)$ & $0(0 \%)$ & $1(4 \%)$ & $0(0 \%)$ \\
\hline Sensory neuropathy & $8(30 \%)$ & $7(26 \%)$ & $1(4 \%)$ & $0(0 \%)$ & $0(0 \%)$ \\
\hline Vomiting & $6(22 \%)$ & $3(11 \%)$ & $3(11 \%)$ & $0(0 \%)$ & $0(0 \%)$ \\
\hline Infection & $5(19 \%)$ & - & $3(11 \%)$ & $2(7 \%)$ & $0(0 \%)$ \\
\hline
\end{tabular}

Data are presented as $\mathrm{n}(\%)$.

Nab-PTX $100 \mathrm{mg} / \mathrm{m}^{2}$. In the phase II trial, the median PFS of 5.2 months met the primary endpoint, and the lower limit of the 95\%CI for the median PFS was 3.3 months, suggesting that CBDCA plus nab-PTX therapy may be effective for patients with NSCLC and PS 2. The median PFS of platinum combination therapy for NSCLC patients with PS 0-1 has been shown to be 4.0-6.3 months $(4,7,11)$. Therefore, our result was comparable with the reported efficacy of platinum combination therapy for patients with PS 0-1. The ORR was $44 \%$ and is consistent with that of the CA031 study (7). The median OS was 14.0 months. In previous studies, the median OS of platinum combination therapy for NSCLC patients with PS 2 ranged from 4.7 months to 9.5 months $(2,9,12$ 16). Therefore, CBDCA plus Nab-PTX may improve prognosis of NSCLC patients with PS 2.

In our study, patients received CBDCA on day 1 and NabPTX on days 1 and 8, every 21 days. No treatment-related deaths occurred. However, grade 3 or 4 adverse events were observed frequently, and most patients required modification of treatment schedule despite treatment without Nab-PTX on day 15. Okuma et al. conducted a phase II study to assess the efficacy and safety of the CA031 study regimen for elderly NSCLC patients (17). Their study was interrupted because of treatment-related deaths and serious adverse events. The modification of CBDCA plus Nab-PTX therapy should be considered for high-risk NSCLC patients. Gajra et al. reported the results of a phase II trial that evaluated the efficacy of CBDCA (AUC 5 day 1) plus nab-PTX $\left(100 \mathrm{mg} / \mathrm{m}^{2}\right.$ days 1 and 8$)$ combination induction and nabPTX monotherapy (100 mg/m $\mathrm{m}^{2}$ days 1 and 8$)$ maintenance treatment in patients with NSCLC and PS 2 (16). In that study, the ORR was $30 \%$, and the median PFS was 4.4 months. Although, in our study, the patients did not receive maintenance therapy, the efficacy of treatment was comparable to that study. Moreover, the median OS (7.7 months) was short in that study. In our study, $63 \%$ of patients could receive post-study treatment chemotherapy. Treatment without maintenance therapy can cause reduction of treatment burden or facilitate induction of post-treatment chemotherapy. Our study treatment may be more reasonable for high-risk patients such as those with PS score of 2 .

CBDCA plus pemetrexed therapy is reportedly effective among patients with advanced non-Sq NSCLC and PS 2 (2). Our study demonstrated the favorable efficacy of CBDCA plus Nab-PTX for non-Sq NSCLC (ORR: 45\%; median PFS: 5.2 months; median OS: 14.2 months). The efficacy in patients with $\mathrm{Sq}$ was also favorable (ORR: 40\%; median PFS: 3.7 months; median OS: 9.0 months). Relative to patients with non-Sq, patients with Sq had shorter PFS and OS. However, the results in Sq patients were comparable with those in previous reports $(9,12-16)$. Our study excluded patients who had interstitial pneumonia with a usual interstitial pneumonia pattern, while Usui et al. reported the safety of CBDCA plus Nab-PTX for NSCLC with interstitial pneumonia (18). CBDCA plus Nab-PTX may be feasible for patients who are ineligible for pemetrexed and may be a reasonable treatment option for NSCLC patients with PS 2.

The present study has several limitations. First, it was a small single-arm study. Second, patients with PS 2 were a heterogeneous population with variable ages, cancer condition, nutrition statuses, and comorbidities. Our study did not consider the reason of PS 2 and could not assess the efficacy and safety according to the reason of PS worsening. 
Third, immunotherapies are becoming important first-line treatments for lung cancer (19). Although only one patient had been treated with immune checkpoint inhibitor before our study treatment, prior treatment with immune checkpoint inhibitor might be beneficial for the other patients. Further studies are needed to establish the optimal treatment modality for NSCLC patients with PS 2.

Recent studies have reported the efficacy of platinum combination chemotherapy plus immune checkpoint inhibitor (20-23). The combination of CBDCA, nab-PTX, and immune checkpoint inhibitor therapy has been shown to be effective for NSCLC patients with PS 0 or $1(21,23)$. The results of our study indicated that CBDCA plus Nab-PTX is tolerable for NSCLC patients with PS 2, and this finding is similar to that reported by Gajra et al. (16). A prospective study to verify the efficacy and safety of the combination of CBDCA, nab-PTX, and immune checkpoint inhibitor therapy for NSCLC patients with PS 2 is needed.

In conclusion, CBDCA plus Nab-PTX therapy demonstrates promising efficacy and safety for patients with advanced NSCLC and PS of 2.

\section{Conflicts of Interest}

Kazuhisa Nakashima, Haruyasu Murakami, and Hiroshige Yoshioka have received honoraria from Taiho Pharmaceutical Co., Ltd Nobuyuki Yamamoto has received grants and honoraria from Taiho Pharmaceutical Co., Ltd. The other Authors declare no conflicts of interest.

\section{Authors' Contributions:}

Kazuhisa Nakashima: Corresponding Author. Creating the study protocol, recruitment of patients, and writing the manuscript; Hiroaki Akamatsu: Creating the study protocol, recruitment of patients, and reviewing the manuscript; Haruyasu Murakami: Creating the study protocol, recruitment of patients, and writing the manuscript; Takashi Niwa: Recruitment of patients and reviewing the manuscript; Yasuo Iwamoto: Recruitment of patients and reviewing the manuscript; Yuichi Ozawa: Recruitment of patients and reviewing the manuscript; Toshihide Yokoyama: Recruitment of patients and reviewing the manuscript; Hiroyasu Shoda: Recruitment of patients and reviewing the manuscript; Nobuyuki Yamamoto: Recruitment of patients and reviewing the manuscript; Hiroshige Yoshioka: Recruitment of patients and reviewing the manuscript; Ken Masuda: Recruitment of patients and reviewing the manuscript; Tateaki Naito: Recruitment of patients and reviewing the manuscript; Keita Mori: Primary biostatistician of this study. Creating the study protocol, statistical analysis, and reviewing the manuscript; Toshiaki Takahashi: Recruitment of patients and reviewing the manuscript.

\section{Acknowledgements}

The Authors would like to thank Editage (www.editage.jp) for English language editing.

\section{Funding}

This research did not receive any specific grant from funding agencies in the public, commercial, or not-for-profit sectors.

\section{References}

1 NCCN Clinical Practice Guideline in Oncology: Non-Small Cell Lung Cancer. Version7.2015. http://www.nccn.org (accessed 28 December 2018).

2 Zukin M, Barrios CH, Pereira JR, Ribeiro Rde A, Beato CA, do Nascimento YN, Murad A, Franke FA, Precivale M, Araujo LH, Baldotto CS, Vieira FM, Small IA, Ferreira CG and Lilenbaum RC: Randomized phase III trial of single-agent pemetrexed versus carboplatin and pemetrexed in patients with advanced non-small-cell lung cancer and Eastern Cooperative Oncology Group performance status of 2. J Clin Oncol 31: 2849-2853, 2013. PMID: 23775961, DOI: 10.1200/JCO.2012.48.1911

3 Sweeney CJ, Zhu J, Sandler AB, Schiller J, Belani CP, Langer C, Krook J, Harrington D and Johnson DH: Outcome of patients with a performance status of 2 in Eastern Cooperative Oncology Group Study E1594: A Phase II trial in patients with metastatic non-small cell lung carcinoma. Cancer 92: 2639-2647, 2001. PMID: 11745199

4 Scagliotti GV, Parikh P, von Pawel J, Biesma B, Vansteenkiste J, Manegold C, Serwatowski P, Gatzemeier U, Digumarti R, Zukin M, Lee JS, Mellemgaard A, Park K, Patil S, Rolski J, Goksel T, de Marinis F, Simms L, Sugarman KP and Gandara D: Phase III study comparing cisplatin plus gemcitabine with cisplatin plus pemetrexed in chemotherapy-naive patients with advanced-stage non-small-cell lung cancer. J Clin Oncol 26: 3543-3551, 2008. PMID: 18506025, DOI: 10.1200/JCO.2007. 15.0375

5 Kato M, Shukuya T, Takahashi F, Mori K, Suina K, Asao T, Kanemaru R, Honma Y, Muraki K, Sugano K, Shibayama R, Koyama R, Shimada N and Takahashi K: Pemetrexed for advanced non-small cell lung cancer patients with interstitial lung disease. BMC Cancer 14: 508, 2014. PMID: 25012241, DOI: $10.1186 / 1471-2407-14-508$

6 Mita AC, Sweeney CJ, Baker SD, Goetz A, Hammond LA, Patnaik A, Tolcher AW, Villalona-Calero M, Sandler A, Chaudhuri T, Molpus K, Latz JE, Simms L, Chaudhary AK, Johnson RD, Rowinsky EK and Takimoto CH: Phase I and pharmacokinetic study of pemetrexed administered every 3 weeks to advanced cancer patients with normal and impaired renal function. J Clin Oncol 24: 552-562, 2006. PMID: 16391300, DOI: $10.1200 / J C O .2004 .00 .9720$

7 Socinski MA, Bondarenko I, Karaseva NA, Makhson AM, Vynnychenko I, Okamoto I, Hon JK, Hirsh V, Bhar P, Zhang H, Iglesias JL and Renschler MF: Weekly nab-paclitaxel in combination with carboplatin versus solvent-based paclitaxel plus carboplatin as first-line therapy in patients with advanced non-small-cell lung cancer: final results of a phase III trial. J Clin Oncol 30: 2055-2062, 2012. PMID: 22547591, DOI: 10.1200/JCO.2011.39.5848

8 Socinski MA, Langer CJ, Okamoto I, Hon JK, Hirsh V, Dakhil SR, Page RD, Orsini J, Zhang H and Renschler MF: Safety and efficacy of weekly nab-paclitaxel in combination with carboplatin as first-line therapy in elderly patients with advanced non-small-cell lung cancer. Ann Oncol 24: 314-321, 2013. PMID: 23123509, DOI: 10.1093/annonc/mds461 
9 Saito H, Nakagawa K, Takeda K, Iwamoto Y, Ando M, Maeda M, Katakami N, Nakano $\mathrm{T}$, Kurata $\mathrm{T}$ and Fukuoka $\mathrm{M}$ : Randomized phase II study of carboplatin-paclitaxel or gemcitabine-vinorelbine in patients with advanced non-small cell lung cancer and a performance status of 2: West Japan Thoracic Oncology Group 0004. Am J Clin Oncol 35: 58-63, 2012. PMID: 21293243, DOI: 10.1097/COC.0b013e318201a0f3

10. Brookmeyer R and Crowley J: A confidence interval for the median survival time. Biometrics 38: 29-41, 1982. DOI: $10.2307 / 2530286$

11. Ohe Y, Ohashi Y, Kubota K, Tamura T, Nakagawa K, Negoro S, Nishiwaki Y, Saijo N, Ariyoshi Y and Fukuoka M: Randomized phase III study of cisplatin plus irinotecan versus carboplatin plus paclitaxel, cisplatin plus gemcitabine, and cisplatin plus vinorelbine for advanced non-small-cell lung cancer: Four-Arm Cooperative Study in Japan. Ann Oncol 18: 317-323, 2007. PMID: 17079694, DOI: 10.1093/annonc/mdl377

12 Lilenbaum RC, Herndon JE 2nd, List MA, Desch C, Watson DM, Miller AA, Graziano SL, Perry MC, Saville W, Chahinian P, Weeks JC, Holland JC and Green MR: Single-agent versus combination chemotherapy in advanced non-small-cell lung cancer: the cancer and leukemia group B (study 9730). J Clin Oncol 23: 190-196, 2005. PMID: 15625373, DOI: 10.1200/ JCO.2005.07.172

13 Kosmidis PA, Dimopoulos MA, Syrigos K, Nicolaides C, Aravantinos G, Boukovinas I, Pectasides D, Fountzilas G, Bafaloukos D, Bacoyiannis C and Kalofonos HP: Gemcitabine versus gemcitabine-carboplatin for patients with advanced nonsmall cell lung cancer and a performance status of 2: a prospective randomized phase II study of the Hellenic Cooperative Oncology Group. J Thorac Oncol 2: 135-140, 2007. PMID: 17410029

14 Lilenbaum R, Axelrod R, Thomas S, Dowlati A, Seigel L, Albert D, Witt K and Botkin D: Randomized phase II trial of erlotinib or standard chemotherapy in patients with advanced non-small-cell lung cancer and a performance status of 2. J Clin Oncol 26: 863869, 2008. PMID: 18281658, DOI: 10.1200/JCO.2007.13.2720

15 Morabito A, Gebbia V, Di Maio M, Cinieri S, Viganò MG, Bianco R, Barbera S, Cavanna L, De Marinis F, Montesarchio V, Costanzo R, Sandomenico C, Montanino A, Mancuso G, Russo P, Nacci A, Giordano P, Daniele G, Piccirillo MC, Rocco G, Gridelli C, Gallo C and Perrone F: Randomized phase III trial of gemcitabine and cisplatin $v s$. gemcitabine alone in patients with advanced non-small cell lung cancer and a performance status of 2: the CAPPA-2 study. Lung Cancer 81: 77-83, 2013. PMID: 23643177, DOI: 10.1016/j.lungcan.2013.04.008

16 Gajra A, Karim NA, Mulford DA, Villaruz LC, Matrana MR, Ali HY, Santos ES, Berry T, Ong TJ, Sanford A, Amiri K and Spigel DR: Nab-paclitaxel-based therapy in underserved patient populations: The ABOUND.PS2 study in patients with NSCLC and a performance status of 2. Front Oncol 8: 253, 2018. PMID: 30087850, DOI: 10.3389/fonc.2018.00253

17 Okuma Y, Hosomi Y, Takahashi S, Nakahara Y, Watanabe K, Nagamata M, Takagi Y and Mikura S: A phase II study of nanoparticle albumin-bound paclitaxel plus carboplatin as the first-line therapy in elderly patients with previously untreated advanced non-small cell lung cancer. Cancer Chemotherapy Pharmacol 78: 383-388, 2016. PMID: 27339149, DOI: $10.1007 /$ s00280-016-3092-9
18 Usui Y, Kenmotsu H, Mori K, Ono A, Yoh K, Baba T, Fujiwara Y, Yamaguchi O, Ko R, Okamoto H, Yamamoto N, Ninomiya T, Ogura T and Kato T: A multicenter single-arm phase II study of nab-paclitaxel/carboplatin for non-small cell lung cancer patients with interstitial lung disease. Ann Oncol 29, 2018. DOI: 10.1093/annonc/mdy292

19 Reck M, Rodríguez-Abreu D, Robinson AG, Hui R, Csőszi T, Fülöp A, Gottfried M, Peled N, Tafreshi A, Cuffe S, O'Brien M, Rao S, Hotta K, Leiby MA, Lubiniecki GM, Shentu Y, Rangwala $\mathrm{R}$ and Brahmer JR: Pembrolizumab versus chemotherapy for PD-L1-Positive Non-Small-Cell Lung Cancer. N Engl J Med 375: 1823-1833, 2016. PMID: 27718847, DOI: 10.1056/NEJMoa1606774

20 Gandhi L, Rodríguez-Abreu D, Gadgeel S, Esteban E, Felip E, De Angelis F, Domine M, Clingan P, Hochmair MJ, Powell SF, Cheng SY, Bischoff HG, Peled N, Grossi F, Jennens RR, Reck M, Hui R, Garon EB, Boyer M, Rubio-Viqueira B, Novello S, Kurata T, Gray JE, Vida J, Wei Z, Yang J, Raftopoulos H, Pietanza MC and Garassino MC: Pembrolizumab plus chemotherapy in metastatic non-small-cell lung cancer. N Engl J Med 378: 20782092, 2018. PMID: 29658856, DOI: 10.1056/NEJMoa1801005

21 Paz-Ares L, Luft A, Vicente D, Tafreshi A, Gümüş M, Mazières J, Hermes B, Çay Şenler F, Csőszi T, Fülöp A, Rodríguez-Cid J, Wilson J, Sugawara S, Kato T, Lee KH, Cheng Y, Novello S, Halmos B, Li X, Lubiniecki GM, Piperdi B and Kowalski DM: Pembrolizumab plus chemotherapy for squamous non-small-cell lung cancer. N Engl J Med 379: 2040-2051, 2018. PMID: 30280635, DOI: 10.1056/NEJMoa1810865

22 Socinski MA, Jotte RM, Cappuzzo F, Orlandi F, Stroyakovskiy D, Nogami N, Rodríguez-Abreu D, Moro-Sibilot D, Thomas CA, Barlesi F, Finley G, Kelsch C, Lee A, Coleman S, Deng Y, Shen Y, Kowanetz M, Lopez-Chavez A, Sandler A and Reck M: Atezolizumab for first-line treatment of metastatic nonsquamous NSCLC. N Engl J Med 378: 2288-2301, 2018. PMID: 29863955, DOI: 10.1056/NEJMoa1716948

23 Jotte RM, Cappuzzo F, Vynnychenko I, Stroyakovskiy D, Rodriguez Abreu D, Hussein MA, Soo RA, Conter HJ, Kozuki T, Silva C, Graupner V, Sun S, Lin RS, Kelsch C, Kowanetz M, Hoang T, Sandler A and Socinski MA: IMpower131: Primary PFS and safety analysis of a randomized phase III study of atezolizumab + carboplatin + paclitaxel or nab-paclitaxel $v s$. carboplatin + nab-paclitaxel as 1L therapy in advanced squamous NSCLC. J Clin Oncol 36 suppl: abstr LBA9000, 2018. 